\title{
Thermal Analysis and Testing of Candidate Materials for PAIDAE Inflatable Aeroshell
}

\author{
Joseph A. Del Corso, Walter E. Bruce, III, Kaitlin A. Liles ${ }^{1}$, and Stephen J. Hughes ${ }^{2}$ \\ NASA Langley Research Center, Hampton, VA, 23681
}

\begin{abstract}
The Program to Advance Inflatable-Decelerators for Atmospheric Entry (PAIDAE) is a NASA project tasked with developing and evaluating viable inflatable-decelerator aeroshell geometries and materials. Thermal analysis of material layups supporting an inflatable aeroshell was completed in order to identify expected material response, failure times, and to establish an experimental test matrix to keep barrier layer materials from reaching critical temperature limits during thermal soak. Material layups were then tested in the 8foot High Temperature Tunnel (8'HTT), where they were subjected to hypersonic aerothermal heating conditions, similar to those expected for a Mars entry. This paper presents a broad overview of the thermal analysis supporting multiple materials, and layup configurations tested in the 8'HTT at flight conditions similar to those that would be experienced during Mars entry trajectories. Direct comparison of TPS samples tested in the 8'HTT verify that the thermal model accurately predicted temperature profiles when there are up to four materials in the test layup. As the number of material layers in each test layup increase ( $>4)$, the accuracy of the prediction decreases significantly. The inaccuracy of the model predictions for layups with more than four material layers is believed to be a result of the contact resistance values used throughout the model being inaccurate. In addition, the harsh environment of the 8'HTT, including hot gas penetrating through the material layers, could also be a contributing factor.
\end{abstract}

\section{Introduction}

$\mathrm{T}$ he Program to Advance Inflatable-Decelerators for Atmospheric Entry (PAIDAE) is a NASA project tasked with developing and evaluating viable inflatable-decelerator aeroshell geometries and materials. Thermal analysis of material layups supporting an inflatable aeroshell was completed in order to identify expected material response, failure times, and to establish an experimental test matrix to keep barrier layer materials from reaching critical temperature limits during thermal soak. Material layups were then tested in the 8-foot High Temperature Tunnel (8'HTT), where they were subjected to hypersonic aerothermal heating conditions. Details will be presented of the thermal analysis performed, as well as all relevant information necessary to reproduce the analysis, and provide an overview of the sled and TPS coupon test configuration, 8'HTT conditions, and temperature results.

\section{Thermal Model and Tools}

Material layups and thermal protection system (TPS) coupons were modeled and evaluated using MSC Patran Thermal $^{1}$, a resistor analysis tool. A TPS layup is composed of a number of fabric, felt and film materials sandwiched together. Materials are then stretched over an aluminum frame and held in place with an aluminum tension ring. The materials, frame, and tension ring are collectively referred to as a TPS coupon, or simply a coupon. The coupon structure is surrounded by silica tiles. The gap between the TPS coupon and silica tiles was

\footnotetext{
${ }^{1}$ Aerospace Engineers, SED/Structural and Thermal Systems Branch, MS431
}

${ }^{2}$ Aerospace Engineer, SED/Material Structures Branch, MS432 
filled with Nextel rope and Saureisen paste. One-dimensional, through-thickness analysis was used to establish a baseline quick-look at expected temperature profiles. Three-dimensional geometry, illustrated in Figure 1, was modeled to evaluate the thermal effect of the aluminum frame and the surrounding gap-filler materials and silica tiles on the temperature distribution across the material surface.

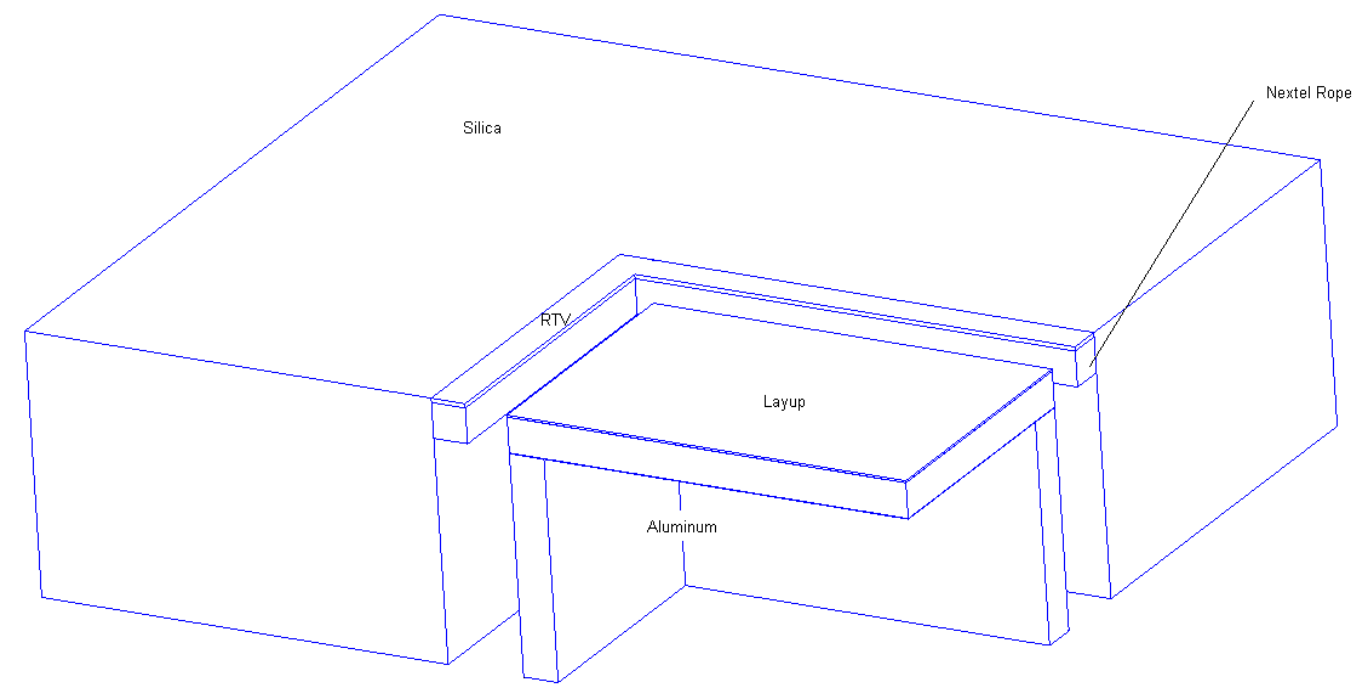

Figure 1. 3D Model of TPS Coupon (quarter model).

A three-dimensional model was used to establish thermocouple locations, and to validate results from 1-D analysis near the center of the TPS coupons. Three-dimensional analysis computation times were over 10-12 hours for a single layup, where 1-D analyses had only 30 seconds to 1 minute durations. Once the 1-D model results were validated using the 3-D model, all subsequent changes to the run matrix (run conditions, heat rates, durations, etc.) were evaluated using the 1-D model.

\section{Materials and Layups}

TPS coupons were made up of multiple material layers (layups) stretched over an aluminum frame, such that a 4" x 6" tensioned surface area was exposed to the hot test gas flow. Each layup was composed of three types of materials sandwiched together. Outer fabrics were exposed directly to the Mach 6.5 flow in the 8'HTT. Insulator fabrics, or low conductivity materials were used to prevent excessive heating through the thickness. Barrier fabrics were intended to act as a gas barrier between the aeroshell bladder and the aeroshell TPS system. The ten layups that were tested in the 8'HTT are provided in Table 1. The material properties used in the thermal models are provided in Table 2. Each material was also tested in a quilted and carbon block supported configuration. The quilted configuration used stitching to secure the material layers together, similar to a quilted blanket. A carbon foam block was inserted behind the material layers on some of the samples to provide backside support to the suspended fabric layup. 
Table 1. PAIDAE Layups

\begin{tabular}{|c|c|c|c|}
\hline Layup \# & Outer Fabrics & Insulators & Barrier \\
\hline 1 & Nextel AF-14 & Pyrogel 6650 & Kapton x 2 \\
\hline 2 & Nextel BF-20 & Pyrogel 6650 & Kapton x 2 \\
\hline 3 & Nextel AF-14 x 2 & Pyrogel 6650 & Kapton x 2 \\
\hline 4 & Nextel BF-20 x 2 & Pyrogel 6650 & Kapton x 2 \\
\hline \multirow{2}{*}{5} & \multirow{2}{*}{ Nextel XN513 } & Refrasil 1800 & \multirow{2}{*}{ Kapton x 2} \\
\hline & & Pyrogel 3350 & \\
\hline 6 & Refrasil C1554-48 & Pyrogel 6650 & Kapton x 2 \\
\hline \multirow{2}{*}{7} & \multirow{2}{*}{ Refrasil C1554-48 } & Refrasil 1800 & \multirow{2}{*}{ Kapton x 2} \\
\hline & & Pyrogel $3350 \times 2$ & \\
\hline \multirow{2}{*}{8} & \multirow{2}{*}{ Refrasil C1554-48 } & Refrasil 2000 & \multirow{2}{*}{ Upilex x 2} \\
\hline & & Pyrogel 6650 & \\
\hline \multirow{2}{*}{9} & \multirow{2}{*}{ Refrasil UC100-28 } & KFA5 & \multirow{2}{*}{ Upilex x 2} \\
\hline & & Pyrogel 3350 & \\
\hline \multirow{2}{*}{10} & \multirow{2}{*}{ T-300 Carbon 1K, 5HS, 24x24 } & KFA5 & \multirow{2}{*}{ Upilex x 2} \\
\hline & & Pyrogel 3350 & \\
\hline
\end{tabular}


Table 2. TPS material properties

\begin{tabular}{|c|c|c|c|c|c|c|}
\hline Material & $\begin{array}{l}\text { Layer } \\
\text { Type }\end{array}$ & $\begin{array}{c}\text { Thicknes } \\
\text { s } \\
\text { (in) }\end{array}$ & $\begin{array}{l}\text { Density } \\
\text { (kg/m3) }\end{array}$ & $\begin{array}{l}\text { Conductivity } \\
\qquad(\mathrm{W} / \mathrm{m}-\mathrm{K})\end{array}$ & $\begin{array}{c}\text { Specific } \\
\text { Heat } \\
(\mathrm{J} / \mathrm{kg}-\mathrm{K})\end{array}$ & Emissivity \\
\hline Nextel AF14 (312) & Outer & 0.014 & 858 & $0.150^{*}$ & 1050 & $0.443^{\star \star \star}$ \\
\hline Nextel BF20 (440) & Outer & 0.02 & 1362 & $0.146^{*}$ & 1130 & $0.443^{\star \star \star}$ \\
\hline Nextel XN513 (720) & Outer & 0.013 & 1151 & $0.148^{*}$ & 1090 & $0.443^{\star \star \star}$ \\
\hline Refrasil C1554-48 & Outer & 0.026 & 924 & 0.865 & $1172^{\star *}$ & 0.7 \\
\hline Refrasil UC100-28 & Outer & 0.015 & 890 & 0.865 & $1172^{\star *}$ & 0.2 \\
\hline Hexcel 282 Carbon & Outer & 0.0087 & 891 & 0.5 & 1000 & 0.9 \\
\hline $\begin{array}{l}\text { Pyrogel } 6650 \\
(5223)\end{array}$ & $\begin{array}{c}\text { Insulato } \\
r\end{array}$ & 0.25 & 110 & $0.030^{*}$ & 1046 & \\
\hline Pyrogel 5401 & $\begin{array}{c}\text { Insulato } \\
r\end{array}$ & 0.0625 & 170 & $0.0248^{\star}$ & 1046 & \\
\hline Refrasil 1800 & $\begin{array}{c}\text { Insulato } \\
r\end{array}$ & 0.125 & 156 & $0.085^{\star}$ & $1172^{\star \star}$ & \\
\hline Refrasil 2000 & $\begin{array}{c}\text { Insulato } \\
r\end{array}$ & 0.125 & 180 & $0.095^{*}$ & $1172^{\star \star}$ & \\
\hline KFA5 & $\underset{r}{\text { Insulato }}$ & 0.236 & 98 & 0.25 & 1250 & \\
\hline Kapton & Barrier & 0.001 & 1468 & 0.12 & 1022 & \\
\hline I Inilny & Darrinr & $n \cap \cap 1$ & $117 n$ & $n$ mn & 11 गी & \\
\hline
\end{tabular}

\section{Sled and 8'HTT}

The NASA Langley 8-Foot High Temperature Tunnel (8'HTT), is a combustion-heated hypersonic blow downto-atmosphere wind tunnel that provides flight simulation over a Mach number range from 4 to 7 and an altitude range from 50,000 to 120,000 feet. $^{2}$ (See Figure 2) The free-jet test section is in a 26 -ft diameter vacuum chamber and was able to accommodate the PAIDAE test sled. The test sled was supported by a sting arm, and was injected into the flow using an elevator mechanism (See Figure 3). Notice that Figure 2 and Figure 3 show a scramjet engine installed in the test section where the test sled was installed for the PAIDAE test.

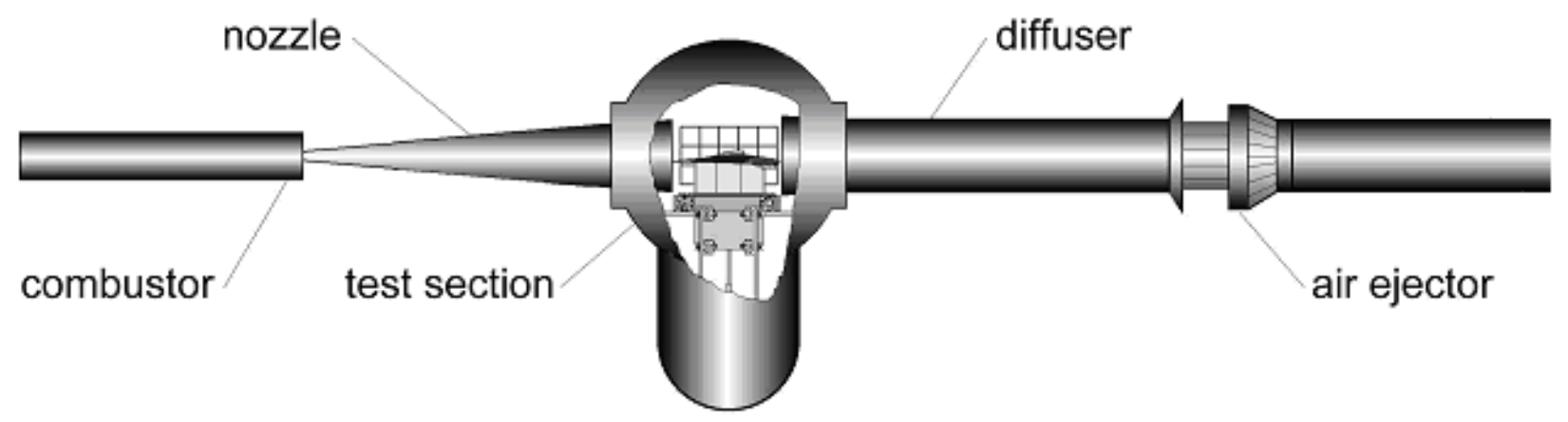

Figure 2. 8-Foot High Temperature Tunnel.

4

American Institute of Aeronautics and Astronautics 


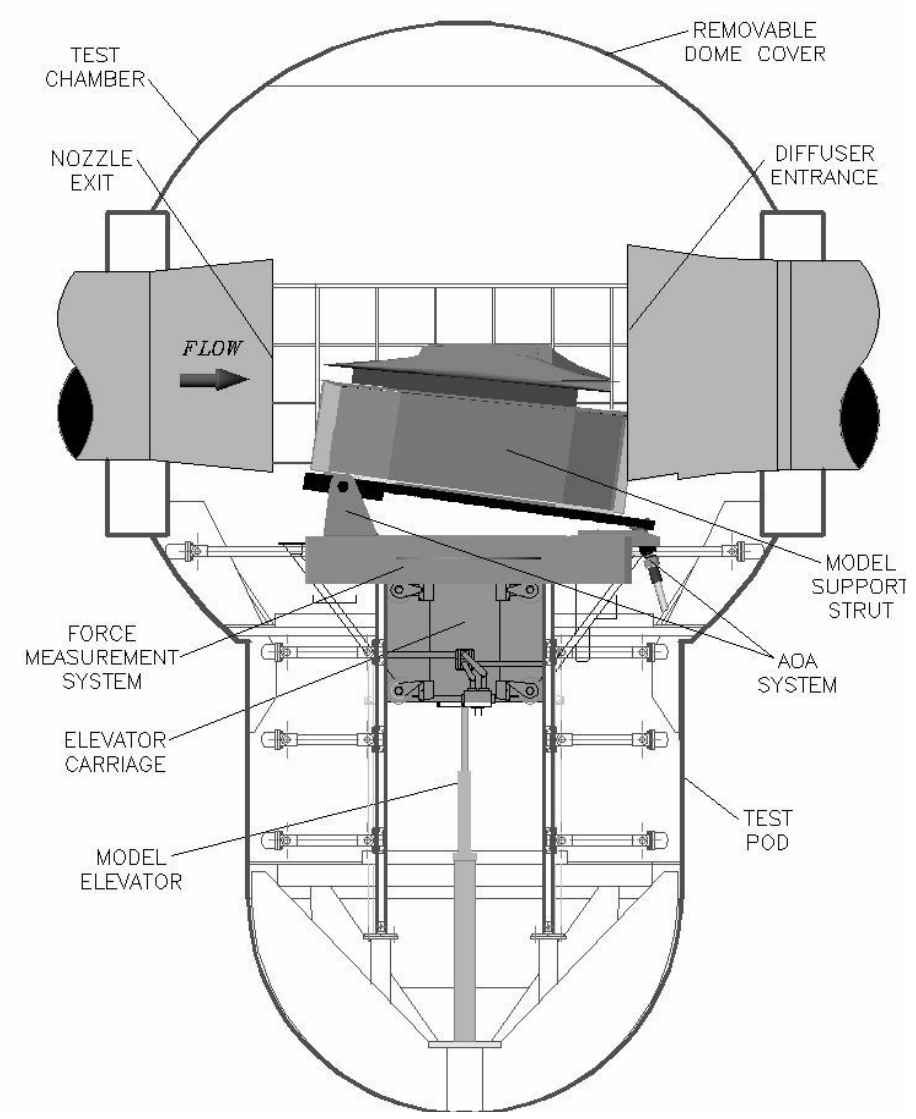

Figure 3. Model Test Section.

TPS layups are bolted into coupon spaces built into silica tiles on the test sled. The test sled has a sharp copper leading edge and hollowed out frame. Three silica panel sections are built into the top of the sled to provide a thermal barrier against the high heat loads for the copper frame. Steel side walls are bolted to either side of the sled to prevent uneven flow, resulting from flow slippage around the sides of the sled. Figure 4 and Figure 5 are provided as an overview of the sled parts and thermal protection system (TPS) coupons relative to the silica tiles. An image of the completed sled in the tunnel is provided in Image 1. 

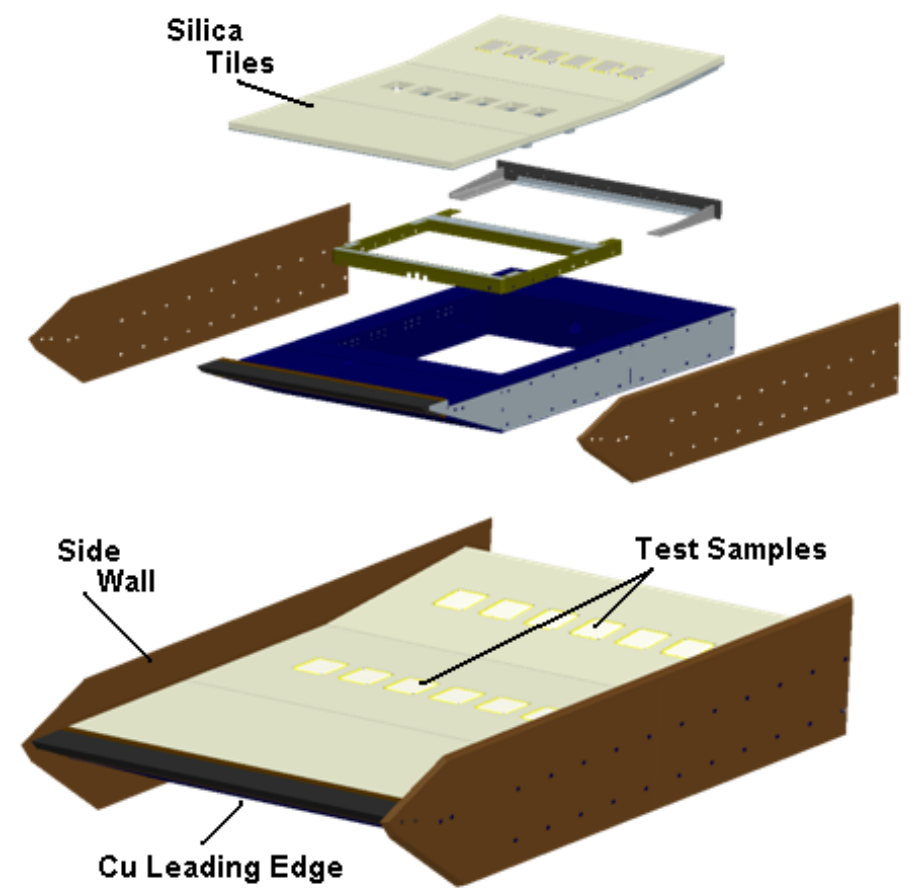

Figure 4. Test sled.

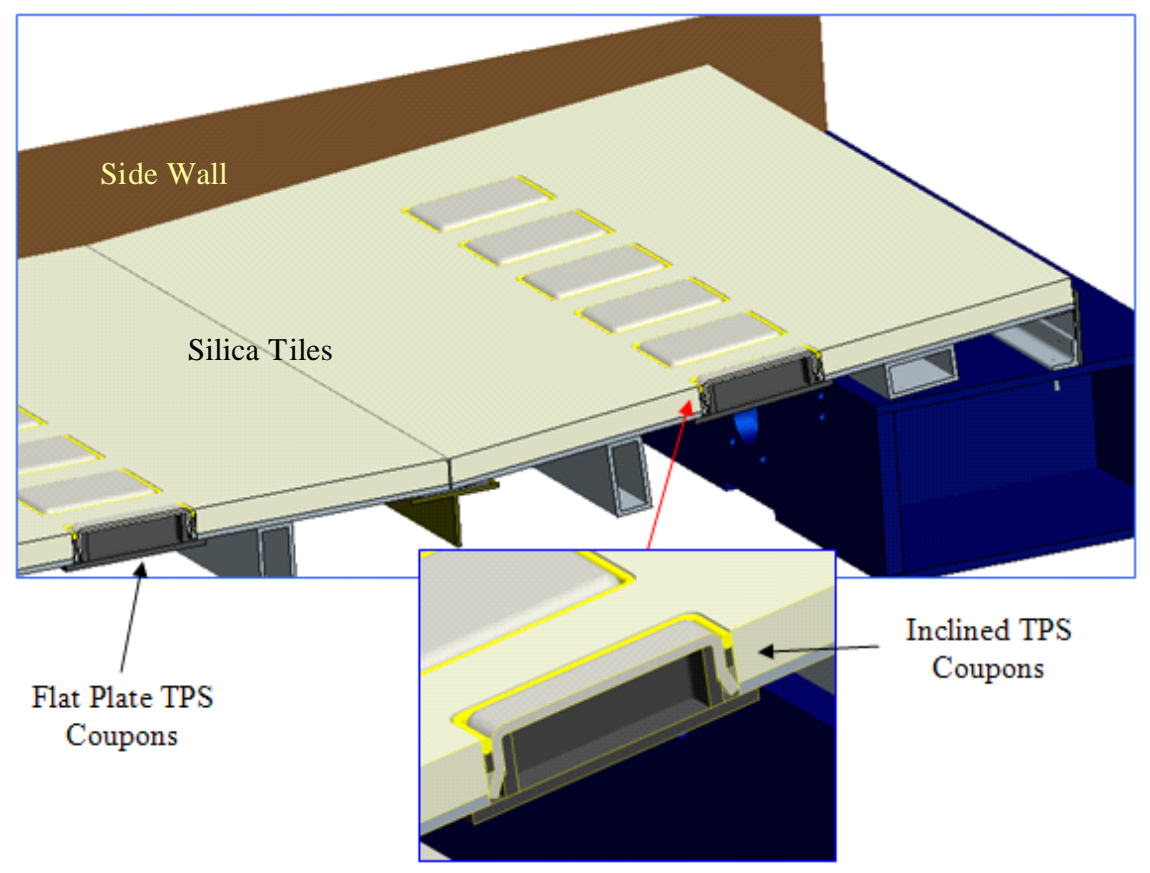

Figure 5. Test Samples and Sled. 


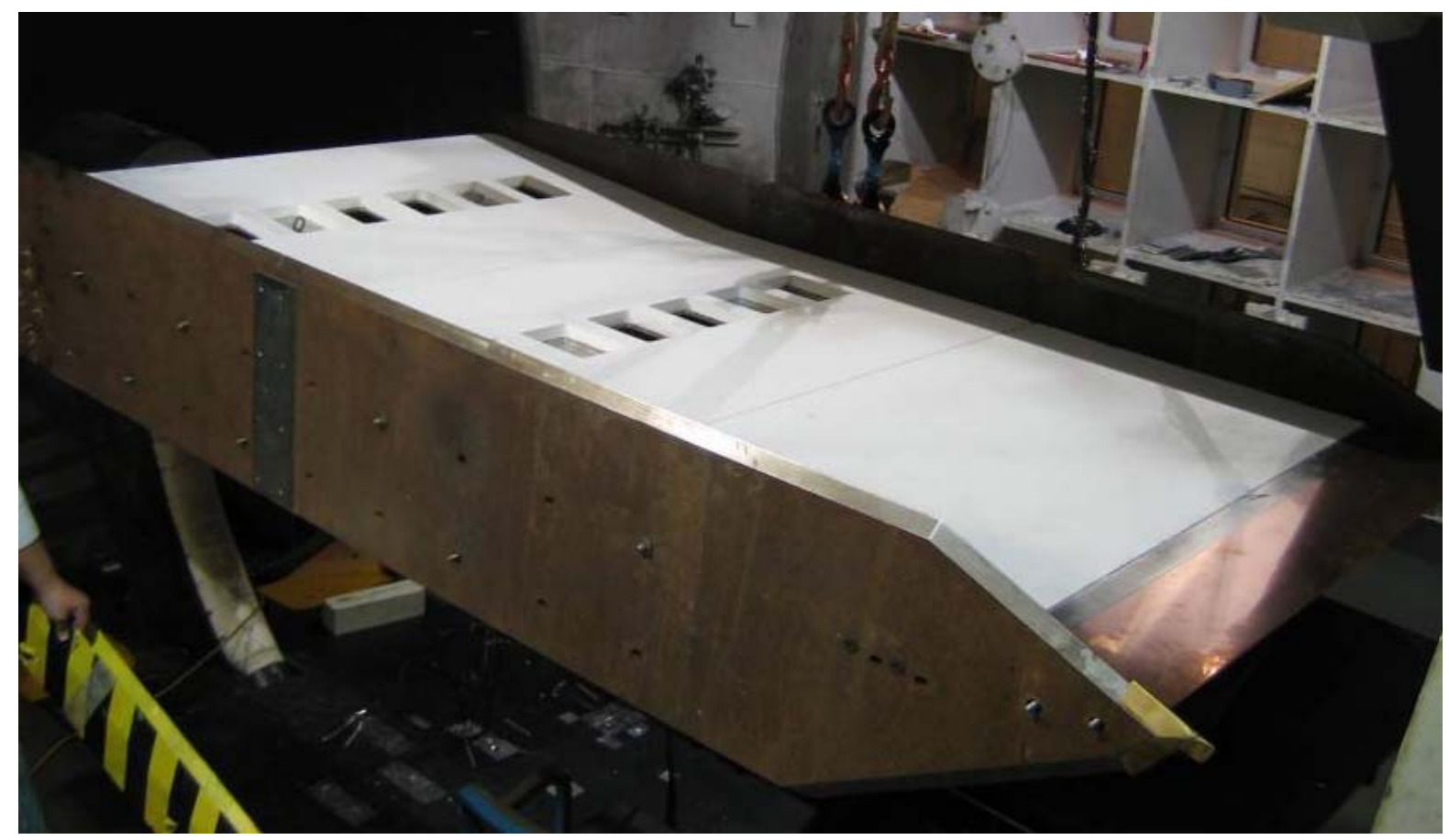

Image 1. PAIDAE Sled without Samples Installed.

\section{Thermal Loads and Boundary Conditions}

TPS coupons, installed in the test sled in the 8'HTT, were subjected to Mach 6.5 tunnel conditions. Computational Fluid Dynamics (CFD) analysis, using VULCAN v6.0.1, was used to determine heat flux loads applied to the TPS coupons as indicated in Figure 7. The condition B and C hot wall heat flux loads are provided in Figure 8, and were applied to the outer fabric materials in the layups. Alternate conditions were evaluated computationally, but were not tested due to tunnel constraints.

$\mathrm{CFD}^{3}$ was performed for a matrix of Sled angles of attack (0, 5, 10, and 15 degrees) and pressure conditions ("low" and "high"). Low and High Pressure conditions are defined in Figure 8, and labeled as Conditions B and C, HighP, respectively. Angles of attack $10^{\circ}$ and $15^{\circ}$ at the "low" pressure condition were eliminated from the matrix by the facility personnel for fear of "un-starting" the tunnel due to flow blockage. Angle of attack of $15^{\circ}$ at the "high" pressure condition was eliminated from the test matrix due to unacceptably high surface pressures predicted on the ramp samples. Zero degrees AoA at the "low" pressure condition did not produce adequate heating to challenge any of the sample layups, even for maximum achievable tunnel run durations. The original test plan called for 10 runs injected at sled angles $5^{\circ}$ (low and high pressure) and $10^{\circ}$ ('high” pressure). The $10^{\circ}$ injection angle was eliminated later during the testing due to the poor performance of test samples on the incline at lower AoA.

The PAIDAE sled was inclined and injected in the 8'HTT at $5^{\circ}$ angle-of-attack, at both low and high pressure flow conditions. The $5^{\circ}$ injection angle is a historical "rule of thumb" for the facility when using the Sled test fixture. In order to attempt to reduce the pressure spike that occurs when the sample crossed the flow boundary at sample injection, a single $0^{\circ}$ Sled AoA injection attempt was made which resulted in a tunnel "un-start", and loss of Layup 1 and 2 test samples. The $0^{\circ}$ injection introduced too large of a blockage in the flow path, and was abandoned as a viable injection and test angle for the sled. The blockage was attributed to the wedge angle on the underside of the leading edge deflecting a large air mass into the tunnel elevator shaft instead of the diffuser. 


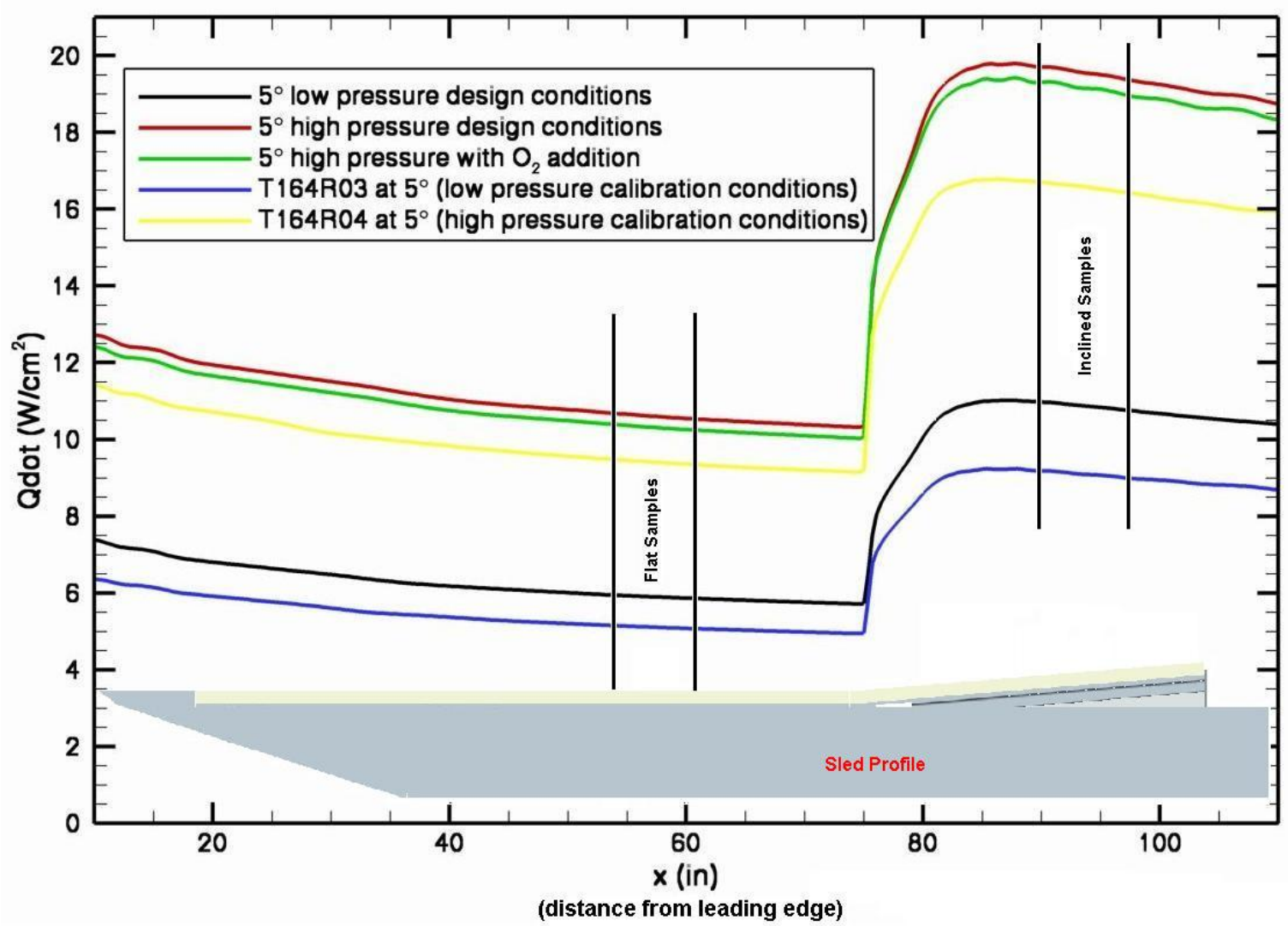

Figure 7. Cold Wall Heat Flux Loads.
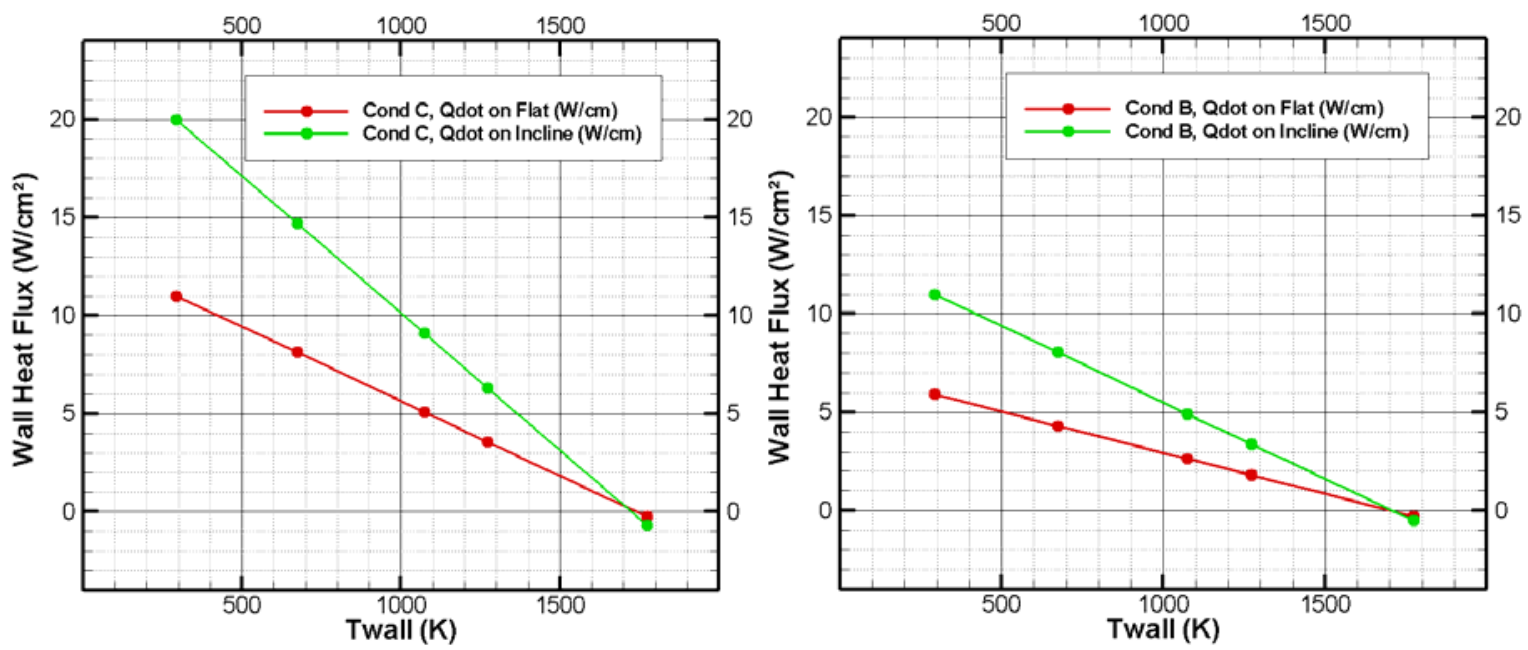

Figure 8. Hot Wall Heat Flux Conditions C (Left), and B (Right).

Preliminary models and initial analysis using cold wall heat flux focused on testing 10 layups at different conditions as indicated in Table 3 and Table 4. 8'HTT tests were constrained to the highlighted conditions due to poor sample performance, and tunnel constraints related to the sled injection angle and flow blockage. Hot wall heat flux was used to refine results. 
Table 3. Thermal Model Flat Conditions.

\begin{tabular}{|c|c|c|c|c|c|c|}
\hline \multirow[b]{2}{*}{ Condition } & \multirow{2}{*}{$\begin{array}{c}\text { Sample } \\
\text { AoA } \\
\text { (deg) }\end{array}$} & \multirow{2}{*}{$\begin{array}{c}\text { Sled } \\
\text { AoA } \\
\text { (deg) }\end{array}$} & \multicolumn{4}{|c|}{ Location 1 (Flat) } \\
\hline & & & $\begin{array}{l}\text { Heat Flux } \\
\text { (W/cm2) }\end{array}$ & $\begin{array}{l}\text { Pressure } \\
\quad(\mathrm{Pa})\end{array}$ & $\begin{array}{l}\text { Thermal Resistance } \\
\text { (m2-K/W) }\end{array}$ & $\begin{array}{c}\text { Convective } \\
\text { Coefficient } \\
\text { (W/m2-K) }\end{array}$ \\
\hline $\bar{A}$ & 0 & 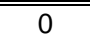 & 3.1 & 850 & 0.12 & 8.333 \\
\hline B & 5 & 5 & 5.9 & 1860 & 0.073 & 13.699 \\
\hline C & 10 & 10 & 11.0 & 3600 & 0.06 & 16.667 \\
\hline $\mathrm{C}$, high $\mathrm{P}$ & 5 & 5 & 11.0 & 3720 & 0.059 & 16.949 \\
\hline $\mathrm{D}$ & 15 & 15 & 16.0 & 6160 & 0.057 & 17.544 \\
\hline $\mathrm{D}$, high $\mathrm{P}$ & 10 & 10 & 19.0 & 7100 & 0.054 & 18.519 \\
\hline$E$, high $P$ & 15 & 15 & 30.0 & 12300 & 0.047 & 21.277 \\
\hline
\end{tabular}

Table 4. Thermal Model Ramp Conditions.

\begin{tabular}{|c|c|c|c|c|c|c|}
\hline \multirow[b]{2}{*}{ Condition } & \multirow[b]{2}{*}{$\begin{array}{c}\text { Sample } \\
\text { AoA } \\
\text { (deg) }\end{array}$} & \multirow[b]{2}{*}{$\begin{array}{l}\text { Sled } \\
\text { AoA } \\
\text { (deg) }\end{array}$} & \multicolumn{4}{|c|}{ Location 2 (Ramp) } \\
\hline & & & $\begin{array}{l}\text { Heat Flux } \\
\text { (W/cm2) }\end{array}$ & Pressure (Pa) & $\begin{array}{l}\text { Thermal Resistance } \\
\text { (m2-K/W) }\end{array}$ & $\begin{array}{c}\text { Convective } \\
\text { Coefficient } \\
(\mathrm{W} / \mathrm{m} 2-\mathrm{K})\end{array}$ \\
\hline$A$ & 5 & 0 & 6.2 & 1860 & 0.073 & 13.699 \\
\hline$B$ & 10 & 5 & 11.0 & 3740 & 0.059 & 16.949 \\
\hline $\mathrm{C}$ & 15 & 10 & 18.0 & 6580 & 0.056 & 17.857 \\
\hline $\mathrm{C}$, high $\mathrm{P}$ & 10 & 5 & 20.0 & 7460 & 0.055 & 18.182 \\
\hline $\mathrm{D}$ & 20 & 15 & 25.0 & 10450 & 0.051 & 19.608 \\
\hline$D$, high $P$ & 15 & 10 & 32.0 & 13100 & 0.045 & 22.222 \\
\hline$E$, high $P$ & 20 & 15 & 46.0 & 20800 & 0.028 & 35.714 \\
\hline
\end{tabular}

The 1-D layup thermal analysis focused on obtaining through-thickness results. The 1-D analysis included an applied heat flux (determined by CFD analysis), conduction through the material layups, radiation to ambient, and an ambient pressure dependent contact resistance (Figure 9). Material properties were determined from a number of sources, and when not readily available were estimated, or based roughly on similar materials with known thermophysical properties.

The 3-D analysis focused on trying to determine what effects the surrounding structures had on the temperature distribution across the coupons. The 3-D analysis was a high fidelity model and was used to determine thermocouple locations such that edge effects were minimized. Edge effects include heat loss to the aluminum frame, decreased contact resistance due to materials being compacted and crimped along the edges, and variable heat loss to the surrounding RTV and Nextel Rope gap fillers. All these factors contribute to temperature gradients near the edges of the frame (i.e. within 1 - 1.5-in of the edge). In addition to the loads and boundary conditions from the 1-D analysis through the coupon layups, conduction to the RTV and Nextel rope was applied to the edge of the material layups, as well as conduction to the silica tiles and aluminum frame (Figure 10). 


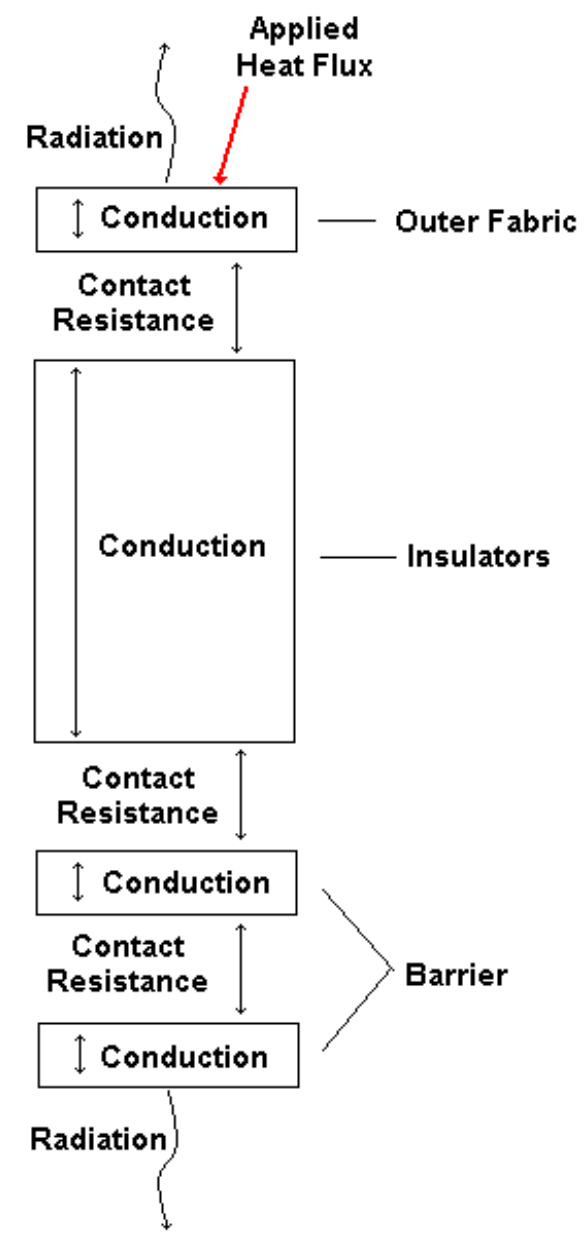

Figure 9. 1D Thermal Boundary Conditions and Loads.

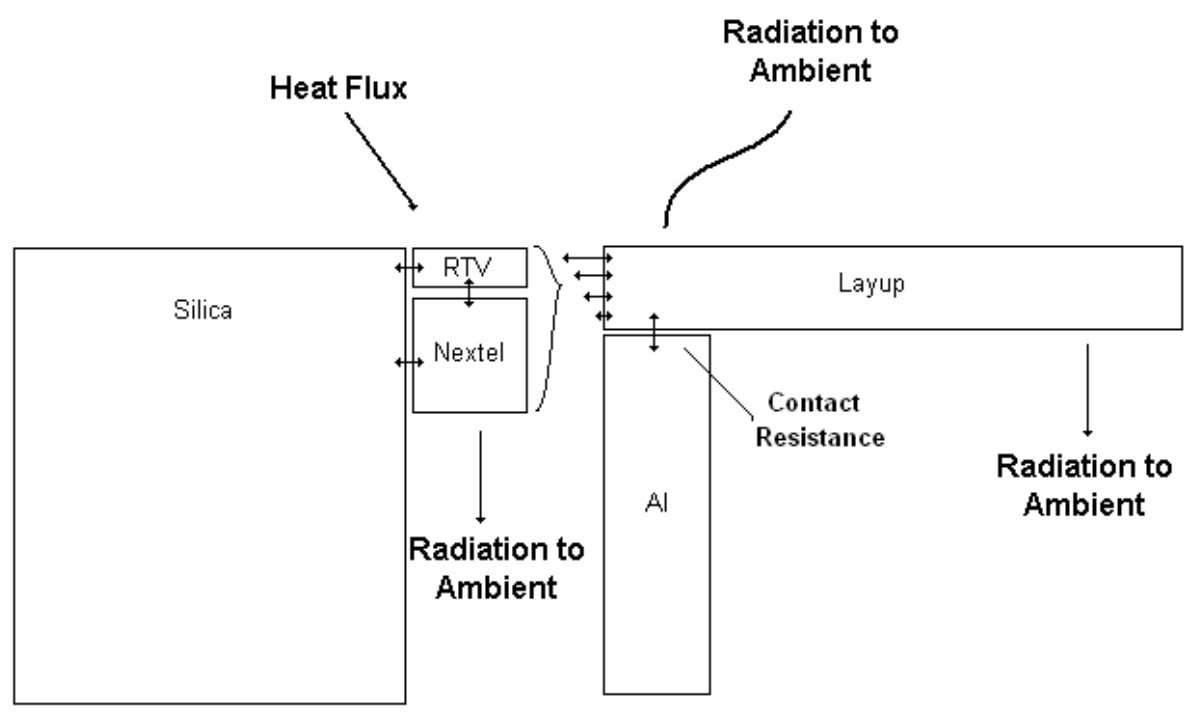

Figure 10. 3D Loads and Boundary Conditions.

American Institute of Aeronautics and Astronautics 
The convective coefficient between the layup edge and RTV/Nextel materials was calculated as indicated in Figure 11. The test model did not include Nextel rope or RTV gap fillers. It was decided prior to the first run to use Saureisen gap filler. Time constraints in modeling the 3-D test setup did not allow for rounded edges of each layup material.
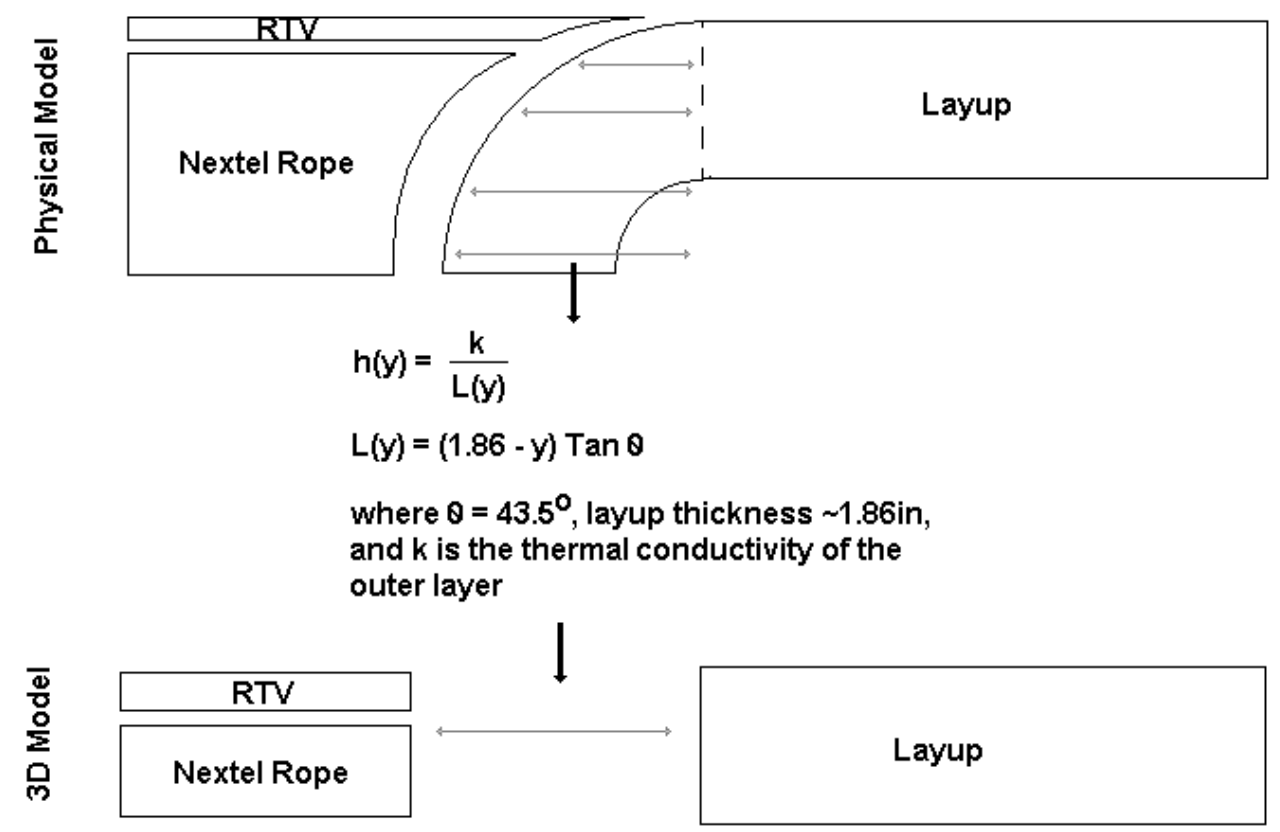

Figure 11. Edge Estimate.

The contact resistance (convective coefficient) applied between materials was based on the tunnel's ambient pressure when on point (in the flow). Contact resistance is dependent on compression pressure, contact area between materials and air gaps from the interstitial weaving. Since material weave and contact area were varied between materials, and because of natural vibrations in the tunnel, as well as differences in pressures on the materials around the edges (where the material plies were clamped to the aluminum coupon frame), contact resistance was difficult to determine accurately. Contact resistance values were determined based on data from the Aero-assist Inflatable Re-entry System (AIRS) analysis and test data ${ }^{4}$ (Report STSB-2006-002) in Figure 12. 


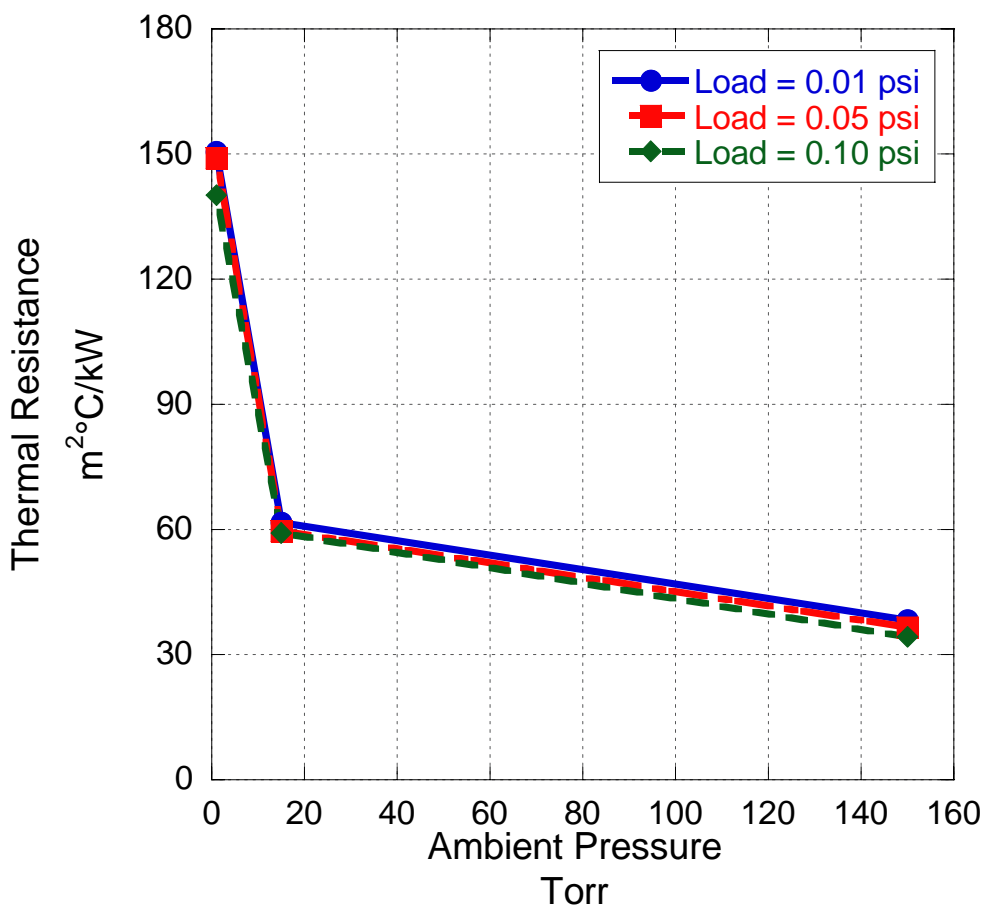

Figure 12. AIRS Analysis Thermal Resistance.

\section{Results}

The 3-D model, with the boundary conditions and loads discussed in the section "Thermal Loads and Boundary Conditions", showed that edge effects are not seen more than 0.5 to 1 -inch from the sidewalls. Figure 13 is an example of a representative temperature contour plot illustrating how the frame sidewalls and surrounding gap filler and silica tiles affect the thermal gradients through the material layups. The temperature gradients across the top layer show the effect of conduction with the holder, and uniform temperatures in the center of the sample. The figure is a quarter symmetry graphic of the full model.

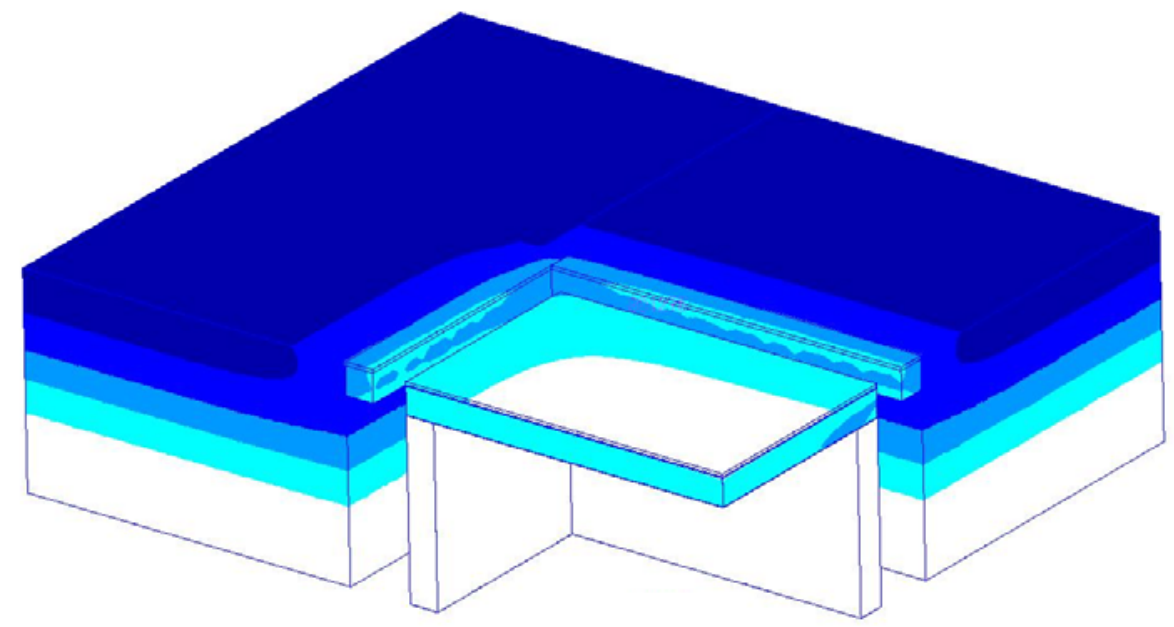

Figure 13. Temperature profile illustrating edge effects.

Figure 14 is a direct comparison of results from 1-D and 3-D TPS coupon centerline analysis. The temperature results from 1-D materials were identical to 3-D material results near the centerline. 
1D: Layup 1, Condition A, Location 1, Duration 90sec

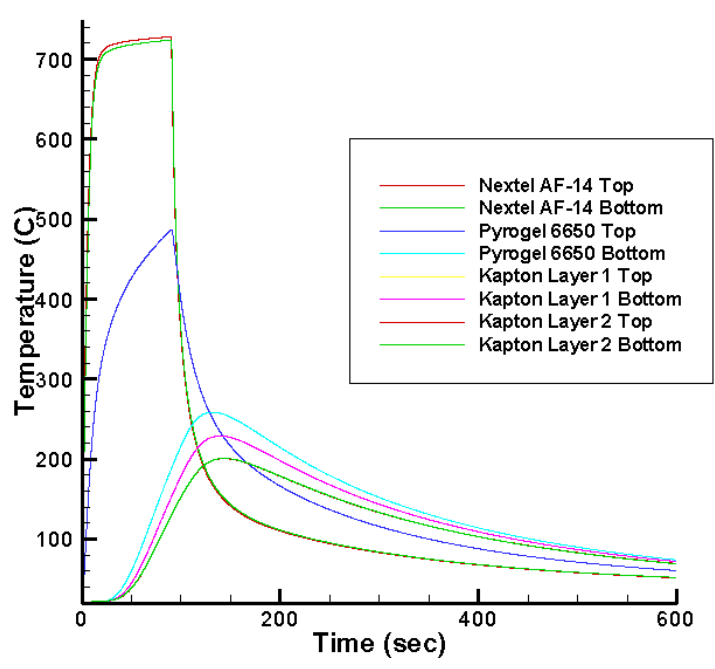

3D: Layup 1, Condition A, Location 1, Duration 90sec

(center of layup)

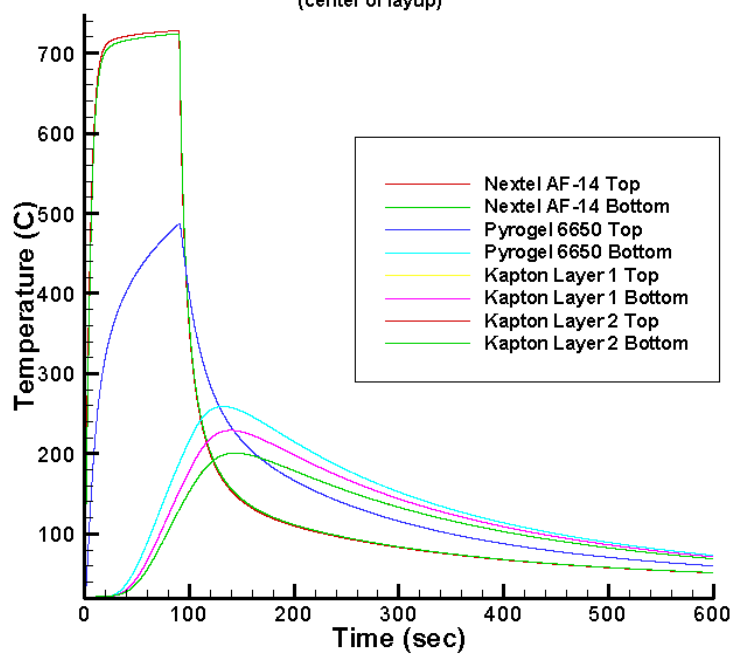

Figure 14. 1D versus 3D results comparison.

After the results of the 1-D model (far from sidewalls) were verified against the 3-D results, 1-D analysis was used to generate all subsequent temperature profiles.

A sample of the full suite of test results for all layups is presented here. Layup 2 coupon, illustrated in Figure 15 , shows where thermocouples were placed relative to each layer. A direct comparison of predictions to results for center and corner thermocouples from TPS coupon layup 2 is plotted in Figure 16 and Figure 17. Analytical data was captured for each layup at the top and bottom of each material, and are represented as thin lines in Figure 16 and Figure 17. Test data, represented by thick lines, was expected to fall between the temperatures measured at the bottom and top of the surrounding materials. The top (6_1-Center, and 6_6-Corner) thermocouple between the Nextel BF-20 and Pyrogel 6650 layers matches the analysis. The center (6_2_Center, 6_3_Center) thermocouples between the Pyrogel 6650 and the top Kapton gas barrier layer, and between the top and bottom Kapton gas barrier layers, were

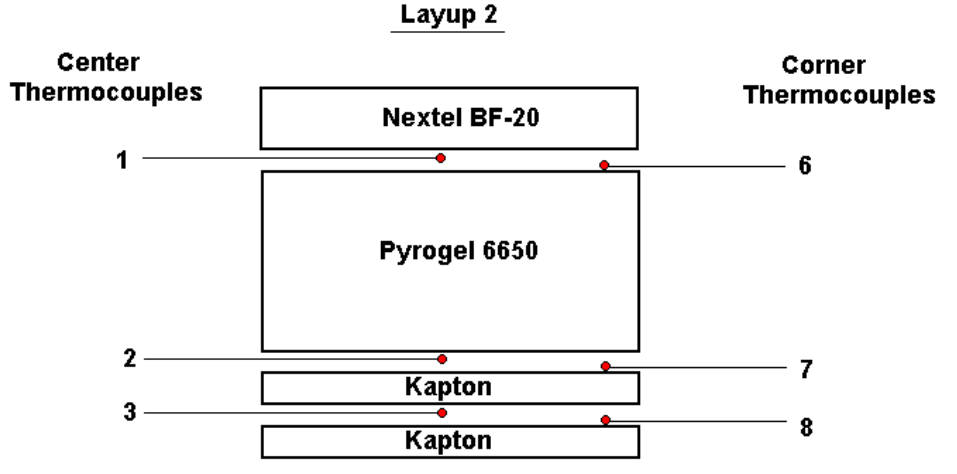

Figure 15. TPS Coupon Layup 2.

higher than predicted. Since the analytical data represents the through-thickness temperature profile at the center of the model coupon, it was reasonable that the corner (6_7-Corner, 6_8-Corner) thermocouples were lower than the predicted temperatures. 


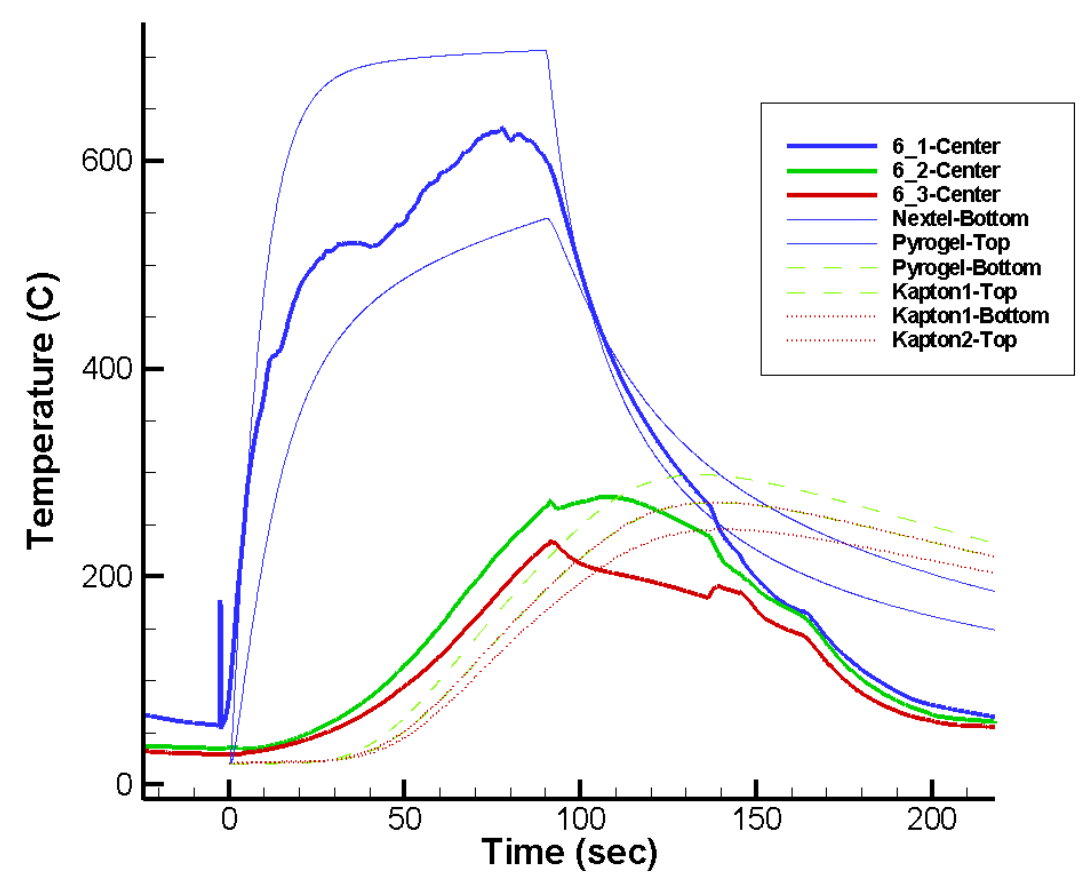

Figure 16. Layup 2 Center Thermocouple Temperature Profile.

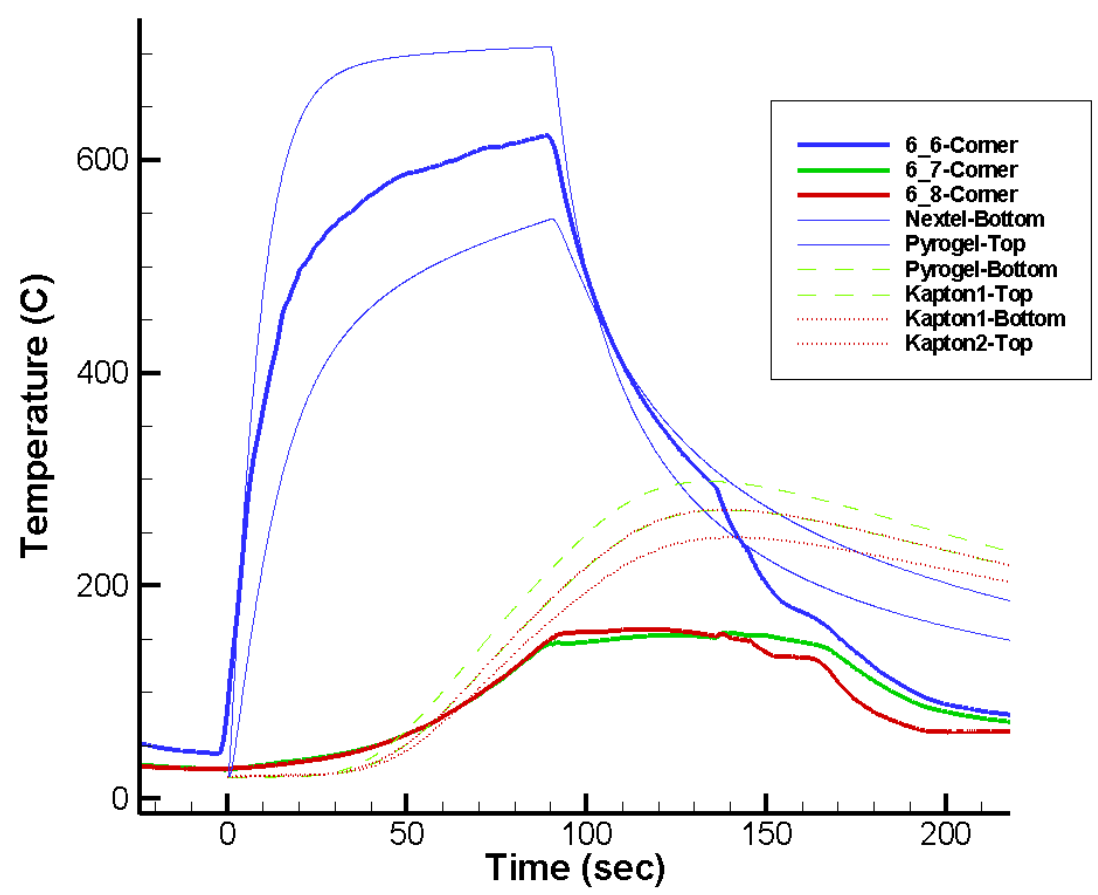

Figure 17. Layup 2 Corner Thermocouple Temperature Profile.

While predicted temperature profiles of layups constrained to three or four layers matched well to test data, the accuracy of the model was found to decrease as the number of layers increased. One contributing factor to the difference in model and test data is attributed to the contact resistance used between materials. Contact resistance values were determined from AIRS data (see Thermal Loads and Boundary Conditions), which takes only ambient pressure into account. For multiple materials stretched over an aluminum frame, the effect of compression pressure

American Institute of Aeronautics and Astronautics 
between materials, and subsequently the contact area of the interstitial material, varies depending on the distance to the edges. It is postulated that edge materials experienced higher interstitial pressures, and therefore lower contact resistance because the materials were pressed together, bent around the corner of a frame, and clamped to prevent movement during construction. It is hypothesized that materials close to the center of the layups would also not respond to the effects of the compression pressure, unless both outer and inner surfaces were forcibly constrained. Quilted layups top layers were constrained, and test data matched results slightly better than non-quilted material layups. The bottom layers of supported layups were constrained with carbon blocks seemed to have little effect on the accuracy of the model when compared to test data.

A hybrid TPS layup (layup 11) was built and tested in the 8'HTT. Layup 11, see Figure 18, was used to evaluate how well the model contact resistances match test data. Figure 19 indicates the Layup 11 model comparison of 8'HTT data to analytical predictions. While the temperature of the top thermocouple matches the predicted values, none of the rest of the measured values matches well with the predictions. A sensitivity study of contact resistance values was performed to see if varying contact resistances affected the accuracy of the through thickness temperature profiles. When contact resistance was increased by a factor of 4 , the analyses matched well with test data, as indicated in Figure 20.

\section{Layup 11}

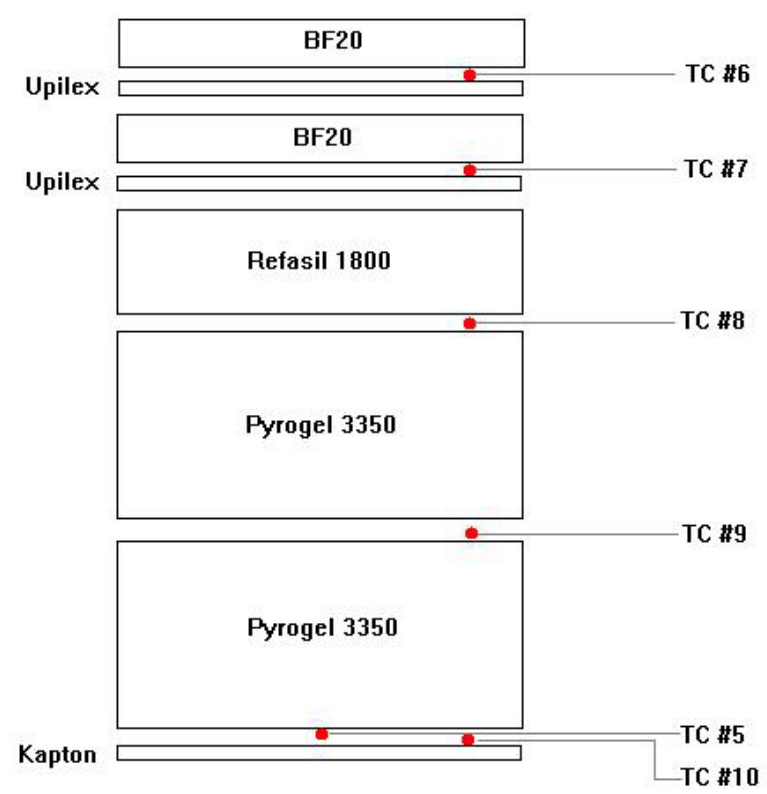

Figure 18. TPS Coupon Layup 11. 


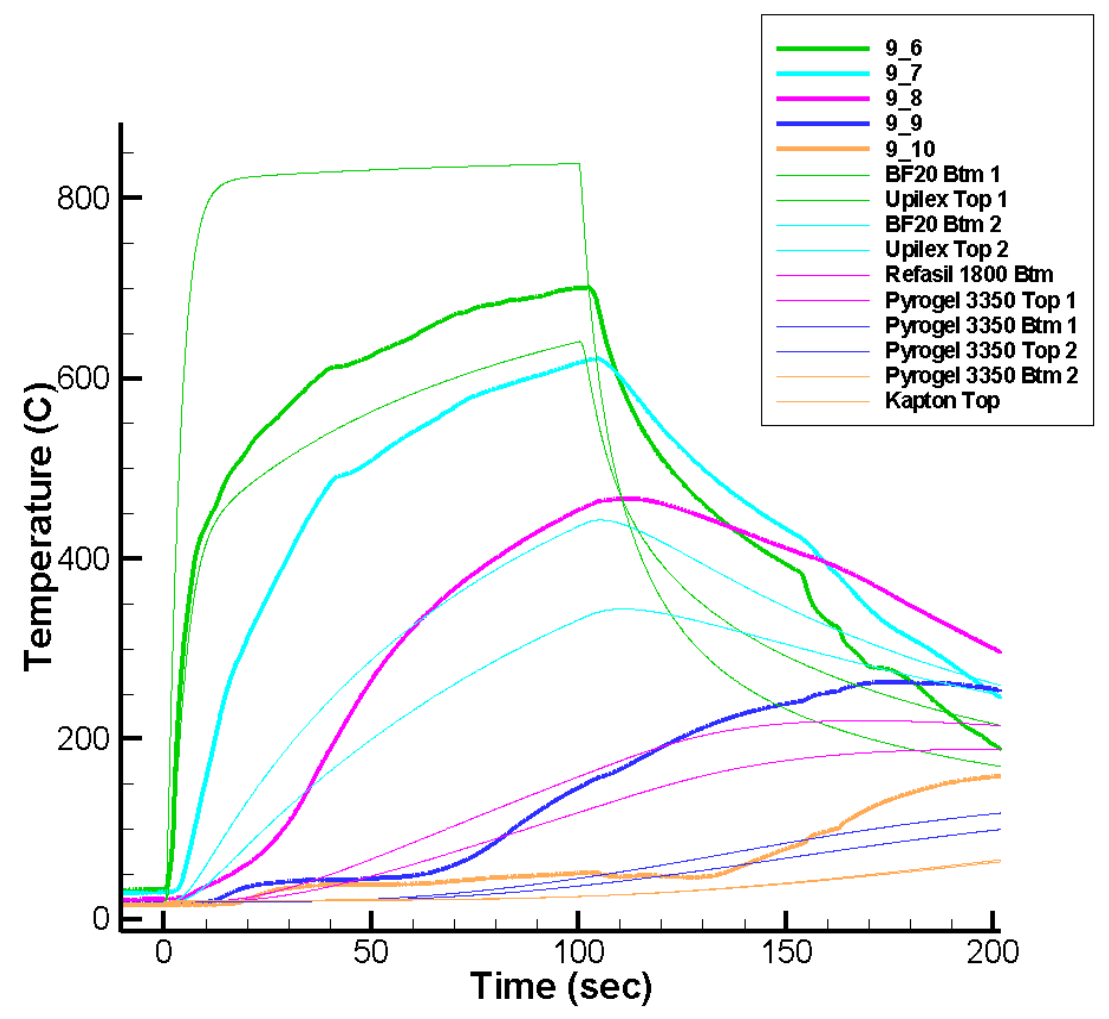

Figure 19. Layup 11 Test Data Comparison.

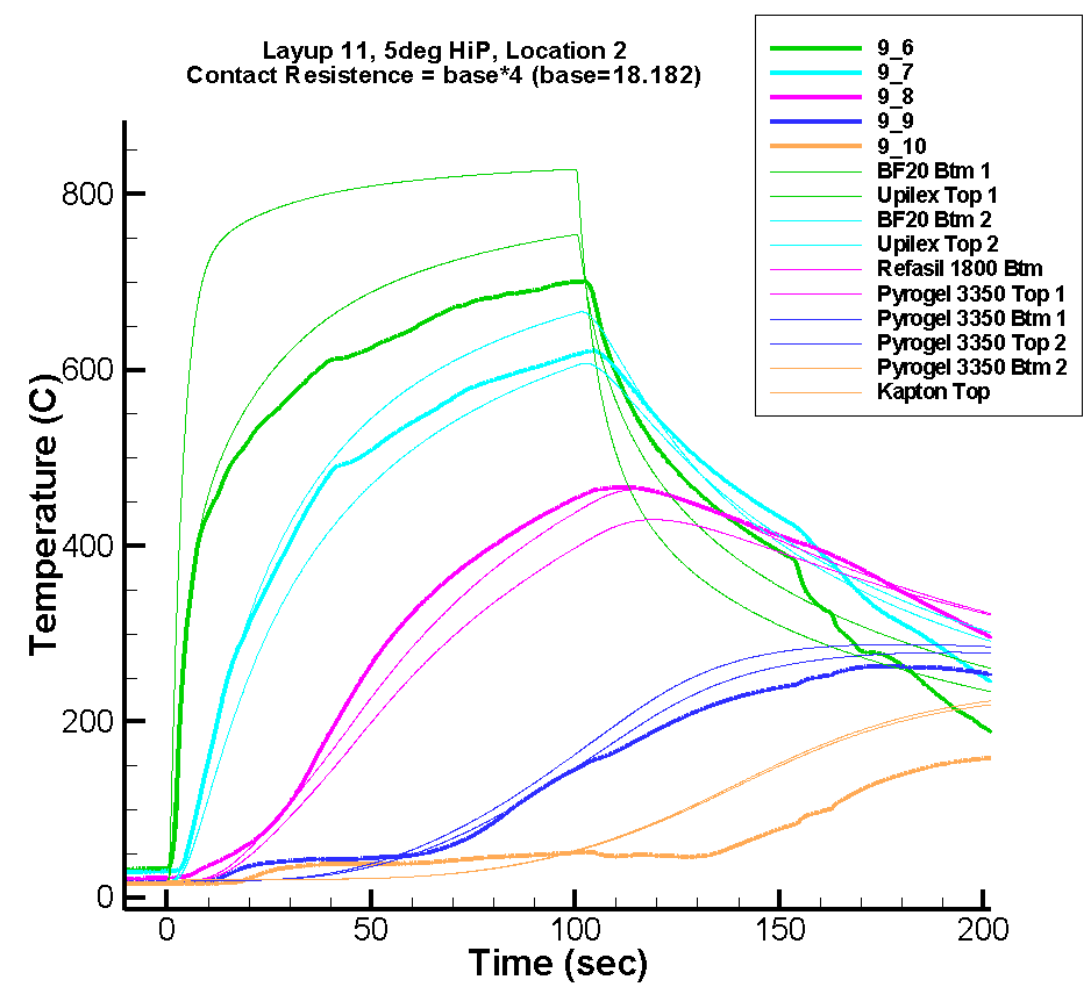

Figure 20. Layup 11 Contact Resistance (x4) Sensitivity Results.

American Institute of Aeronautics and Astronautics 
While the 8'HTT provided a method to test materials, it also came with a number of unforeseen testing problems which likely affected the accuracy of the test samples' measured temperatures compared to model predictions. While the tunnel was ramping up, the sled vibrated violently. The TPS samples experienced the sudden tunnel pull down (pressure drop in the test chamber) which is believed to have caused a pressure imbalance between the cavity pressure and ambient, resulting in the layers being pillowed out from the frame momentarily. When the sled was injected into the test flow (elevator lifting the sled into position in the tunnel chamber), the samples were impacted by a shock moving from the back of the sled to the front across the sled surface as the sled moved into the test flow, through the shear layer, into the center of the test stream. The samples crossed the shear layer again upon removal from the flow at the end of the test. The samples were also exposed to rather sudden pressure changes and vibration as the tunnel started and shutdown. Even though the test sled was not typically in the test stream during these events, a strong shock traversed the test cabin affecting the conditions in the cabin where the sled resided.

\section{Conclusions}

The information outlined in this paper has shown how the PAIDAE thermal models were built, boundary conditions applied, and relevant assumptions made to run the analysis and obtain meaningful results. Direct comparison of TPS samples tested in the 8'HTT verifies that the thermal model accurately predict temperature profiles when there are up to four materials in the test layup. As the number of material layers in each test layup increase, $(>4)$ the accuracy of the prediction decreases significantly. The inaccuracy of the model predictions for layups with more than four material layers is believed to be partly related to the contact resistances used throughout the model being inaccurate, although the violence of the 8'HTT environment, including hot gas penetrating through the material layers could also be a contributing factor. For fewer than four material layers, the AIRS data can be used to determine the contact resistance. For more than four material layers in the layup, using contact resistance from AIRS data does not accurately model the through thickness temperature profiles. Sensitivity studies of layup 11 showed that using a $4 \mathrm{x}$ factor increase of the AIRS data contact resistance value fit the test data spread. It is unknown if the same factor increase of the AIRS data contact resistance values for alternate material samples with greater than four layers would also match test data due to lack of tested samples.

The test samples were subjected to a heat flux of roughly 6,11 , and $20 \mathrm{~W} / \mathrm{cm}^{2}$, and higher shear than would be expected in flight. PAIDAE reports for each set of samples tested in the 8'HTT have been compiled in a project document ${ }^{5}$, and include a complete list of each layup, location, materials, runs, thermal and test results, as well as photographs of the pre- and post-test coupons, each material layer post test, and the notes generated by test engineers during the runs.

\footnotetext{
${ }^{1}$ MSC Patran Users’s Manual, MSC Software Corporation, Santa Ana, CA Version 14.0.018, October 4, 2006.

${ }^{2}$ Harvin, S.F., Cabell, K.F., Mekkes, G.L., and Gallimore, S.D., “Test Capability Enhancements To The NASA Langley 8-Foot High Temperature Tunnel”, JANNAF, 2006.

${ }^{3}$ Ferlemann, P.G. "Analysis of the Material Test Sled During Injection into the 8'HTT Test Flow”, Technical Note 05-523, TEAMS Contract NNL07AA00B, NASA Langley Research Center, October 29, 2008.

${ }^{4}$ Bruce III, Walter E., “Aeroassist Inflatable Reentry System (AIRS) Thermal Protection System (TPS) Thermal Analysis”, STSB-2006-002, February 2006.

${ }^{5}$ Player, Charles, "PAIDAE Thermal Protection System Testing Final Report - FY2008”, PAI-DAE-3.3-012, NASA Langley Research Center, 2008.
} 